\title{
Puiggrós, Adriana, "Adiós, Sarmiento. Educación pública, Iglesia y mercado". Ediciones Colihue. Buenos Aires. 2017.
}

Renzo Tiberi 
Adriana Puiggrós es una destacada pedagoga e investigadora del campo de la educación. Distinguida y reconocida en nuestro país y en la región, ha ocupado cargos como Diputada Nacional, presidente de la Comisión de Educación de esa Cámara, Directora General de Educación de la Provincia de Buenos Aires y Secretaría de Ciencia y Tecnología de la Nación, y es autora de grandes obras como "Imperialismo y educación en América Latina", "La educación popular en América Latina" e "Historia de la educación en Argentina". Su gran trabajo y desarrollo en el campo educativo y pedagógico la ubica como una referencia de importancia para pensar y reflexionar sobre los desafíos que acontecen en estos turbulentos años.

La polémica reaparición de la imagen Domingo Faustino Sarmiento y de la vigencia de la Ley 1420 en los debates electorales de 2015 detonaron para la autora una profunda discusión con relación a la imagen y la figura del "padre del aula" que según ella hoy sigue siendo nombrada tanto por "amigos como enemigos", es decir, por quienes protagonizamos la defensa de la educación pública, gratuita y laica, y por quienes orientan hoy los cañones a su desmantelamiento y destrucción.

Puiggrós afirma que el sistema educativo obligatorio moderno, que ha sido fundado y consolidado por el liberalismo conservador hacia fines del siglo XIX, ha sufrido grandes y decisivos cambios en los últimos años debido a la profundización de las políticas neoliberales que pretenden dejarlo en el pasado y que intentan terminar con el monopolio de la educación por parte de la institución escolar para entregarla en las "manos invisibles" del mercado. Con el objetivo de comprender estas grandes transformaciones que acontecen en la realidad de nuestra educación, "Adiós, Sarmiento" nos propone un recorrido por la historia de las políticas educativas de nuestro país, desde la construcción del sistema hasta la realidad de las últimas décadas signadas por la influencia del neoliberalismo.

En esta obra de gran extensión y riqueza, de casi 400 páginas, organizadas en 18 capítulos y tres secciones, la autora indaga en cada momento histórico el rol del Estado, el financiamiento, y el papel del mercado y la intervención de la iglesia y las religiones, transversali- 
zando desde las primeras páginas la imagen de Sarmiento, su persona, sus ideales, y la recuperación de su figura por los distintos gobiernos que acontecieron en nuestra nación.

En la primera sección vuelca un gran trabajo de investigación, análisis y reflexión de lo que denomina "la fragua del sistema educativo moderno" en la cual logra sintetizar las producciones, debates y discusiones que acontecieron durante gran parte del sigo XIX y finales del XX y que giraron alrededor de la conformación de dicho sistema. Esta sección nos permite adentrarnos en la voz de los y las protagonistas de esas discusiones, principalmente la de Sarmiento, personaje interesante, profundo y a la vez polémico y hasta "contradictorio": hijo de una educación en la cual "exaltación religiosa y política no faltó" y fiel admirador del modelo social y de la religiosidad estadounidense, el sanjuanino simboliza los ideales modernistas y liberales de la generación del ' 37 , a la vez que encarna un fuerte sentimiento por los valores religiosos y morales. En las particularidades del pensamiento sarmientino se sintetizan algunas de las complejas tramas de discusión que fueron moldeando los debates legislativos que dieron forma a la Ley. Los testimonios y discursos recogidos de dos momentos fundamentales como lo fueron el Congreso Pedagógico de 1882 y la discusión parlamentaria previa a la sanción de la 1420 en 1884 alumbran estas particularidades: la secularización de la educación, el lugar de la enseñanza religiosa, el financiamiento y la gestión de los establecimientos, entre otros, fueron los temas fundamentales que las atravesaron.

En la segunda sección, Puiggrós nos introduce en un recorrido por casi todo el siglo XX, partiendo de afirmar que Sarmiento, el prócer, dominó casi todo este siglo permaneciendo en las aulas a través de los gobiernos de todas las posturas, lo que nos convoca sin duda a una reflexión profunda. Desde los primeros gobiernos populares posteriores a la 1420, hasta los años de la última dictadura, afirma que los principios vertebradores de la educación pública se mantuvieron, y a pesar de la inestable relación entre el Estado y la Iglesia, cuya separación según la autora la sociedad argentina nunca quiso resolver, "la escuela pública estaba garantizada". El Congreso Pedagógico de 
1984 motorizado con los nuevos aires de la apertura democrática no logró oxigenar las viejas discusiones y el "empate" entre el sector privatista conservador católico y el sector laico liberal se volvió a materializar en la nombrada bifurcación del sistema escolar donde escuelas privadas y públicas empiezan a tomar caminos marcadamente distintos.

En la última sección nos presenta lo que lapidariamente denomina como "la destrucción del sistema escolar moderno", que había comenzado a asomarse en las definiciones del Congreso Pedagógico. Nos propone aquí un recorrido por el camino que toma el capitalismo y la marcha que emprende el neoliberalismo sobre la educación pública, puntualizando en el avance de las corporaciones sobre los sistemas educativos de Chile y Colombia para luego imbuirse en el caso de nuestro país. Con similitudes y diferencias entre estos casos, encuentra en el gobierno de Carlos Menem, el claro ejemplo de la implementación de las recetas neoliberales, en el acatamiento de las propuestas de los grandes organismos financieros internacionales: la desarticulación y descentralización del sistema educativo nacional estuvo acompañado de la apertura al mercado, la defenestración de la educación pública estatal, la deslegitimación pública de los y las docentes, el avance de la oferta privada y la introducción de la "teoría de la administración" como doctrina cultural del mercado. Es en este momento en el que identifica que los esfuerzos y el camino hacia la constitución de una "educación común" empieza a socavarse.

El avance neoliberal en el sistema educativo argentino va a tener, para la investigadora, la particularidad de encontrarse con la resistencia de los movimientos sociales y sindicales, con la denominada "Marcha Blanca" como máxima expresión, así como de las políticas impulsadas en los tres períodos kirchneristas: los avances en materia legislativa propuestos durante los mandatos de Néstor y Cristina, aunque con algunas limitaciones, representan una clara orientación al fortalecimiento del sistema educativo público. Pero la llegada de Cambiemos al poder es, a juicio de la pedagoga, el comienzo de una estrategia dirigida a la desestructuración del sistema y la apertura descarnada a la inversión privada. Múltiples son los ejemplos que 
recoge en esas últimas páginas para argumentar como un conjunto de grandes empresarios y CEOs dirigen hoy los horizontes políticos de nuestro país, y entre ellos los de la misma educación. La propuesta de Esteban Bullrich 33 de "rescatar" a Sarmiento no es más que una forma de encubrir el "adiós" que el neoliberalismo le quiere decir al padre del aula y a su inconcluso proyecto de una educación común y laica.

En estos tiempos en los que advierte que la cuestión educativa es atravesada por los proyectos de intervención en la formación docente y la mercantilización, la autora nos invita y convoca en las últimas páginas a mantener viva la esperanza y no permitir que se le diga "Good Bye" a Sarmiento. Nos dice que despidamos al "enojón racista y belicista", y que nos permitamos recibir la educación común, gratuita, laica y obligatoriamente como un derecho.

A 100 años de la Reforma Universitaria y en el agitado clima que estamos viviendo quienes formamos parte de la educación pública, "Adiós, Sarmiento" se presenta como una propuesta muy necesaria para reflexionar sobre la realidad que acontece hoy en día en nuestro sistema educativo. Es un material indispensable para los debates educativo del presente. Es, en palabras de la autora, una búsqueda en nuestra historia que permita comprender mejor la actual hegemonía de los mercaderes descarnados, y entender que no se trata de la única salida posible de la sociedad moderna"; una búsqueda de ese sujeto que, muerto Facundo y Sarmiento, no imagina volviendo, sino resinificándose, "no solamente "bárbaro, valiente y audaz para cambiar el mundo, sino sabio, amante, libre”. Ese sujeto, afirma Puiggrós, debe estar germinando en algunos lugares de nuestro país y de América Latina, y es sin duda nuestra responsabilidad, siempre colectiva, la de abonar hacia ese renacer.

Recepción: 15/04/2018

Aceptación: 10/10/2018

33 Ministro de Educación de la Nación desde diciembre de 2015 hasta julio de 2017, durante el actual mandato de Mauricio Macri. 